\title{
Retrieval project for the lost bottom gillnet in Korea
}

\author{
YOUNG-IL AN \\ Gangwon Provincial University, 8-2Jumunjï, Gangnung, Korea
}

SUMMARY: A retrieval project for the lost fishing gear off the east coast of Korea was undertaken to improve the environmental condition of the fishing ground for walleye pollack. Lost gear was retrieved during the off-fishing season between May and August since 1998, by the trawlers; belonging to the Fisheries Training Vessel of Gangwon Provincial University and another to Korea Fishing port Association. A grapnel was designed for retrieving the lost bottom gillnet and trap, by towing on the seabed and hauled up on the vessel. The net weight of the retrieved gillnets was 709t, 461t, 549t and 654t in each year from 1998 to 2001 , respectively. The retrieved amount of bottom gill net per towed mile was $22.74 t, 12.57 \mathrm{t}, 12.45 \mathrm{t}$ and 17.98t, respectively. The retrieved amount per haul was $11.27 \mathrm{t}, 7.48 \mathrm{t}, 8.85 \mathrm{t}$ and $5.84 \mathrm{t}$, respectively. It can therefore be concluded that grapnel is a useful and effective tool for the retrieval project of the lost fishing gear.

\section{KEY WORDS: grapnel, lost bottom gillnet, retrieval, walleye pollack, fishing ground}

\section{INTRODUCTION}

For centuries, people have used ocean as a dumping ground for waste. Fishermen also have been using new fishing gear every year, but discarding or have lost lots of used fishing net in fishing grounds. Since environmental pollution in coastal fishing grounds is accelerating, and over-fishing and exhaustion of major species is getting more prevalent, the issue of harmony between fishery and environment is attracting a lot of attention. It is also important to establish basis of sustainable fishery production through systematic management of the coastal fishing ground environment. ${ }^{1)}$

The nondegradable quality of the nylon is good for the fishing industry, but is also a serious threat to living marine resources when a net made of it gets lost or discarded. ${ }^{2)}$ The amount of gear lost annually probably increases with increased fishing effort and, in some areas, lost gear may outnumber active gear units. ${ }^{3)}$ Lost gillnets and traps can remain and catch marine life for well over a decade. ${ }^{3)}$ If lost or abandoned fishing gear sinks or is lost at the bottom, they may continue to catch commercially valuable crabs and other benthic species for many years. ${ }^{4,5}$ ) The increase in number of lost fishing gears not only obstructs fish migration routes and fishery production activities but also destroys spawning grounds and habitats. Ghost fishing by lost fishing gear may have a considerable impact on the ecological environment. 2,3,5) The controversy over gillnet losses and their continued fishing as ghost gillnets has been a unique issue in the walleye pollack fishing grounds of South Korea for several decades, since the use of bottom gillnets greatly expanded.

This retrieval project aims at maintaining fishery production activities through improvement in fishing ground environment by retrieving lost fishing gear.

\section{MATERIALS AND METHODS}

The Himangbong (G/T 159.71, stern trawler), the Fisheries Training Vessel of the Gangwon Provincial University, in 1998 and 1999, and the Cheongkyung (G/T 303, stern trawler), Korea Fishing port, in 2000 and 20001 were used to retrieve lost fishing gear. Grapnel has been manufactured for the use of retrieving lost fishing gear deposited at the seabed (Fig. 1). Its weight is $200 \mathrm{~kg}$ in case of Himangbong and $400 \mathrm{~kg}$ in case of Cheongkyung and its arm is at an angle of 50 degrees.

The working period included a total of 109 days: from June to July 1998 (24 days); from May to

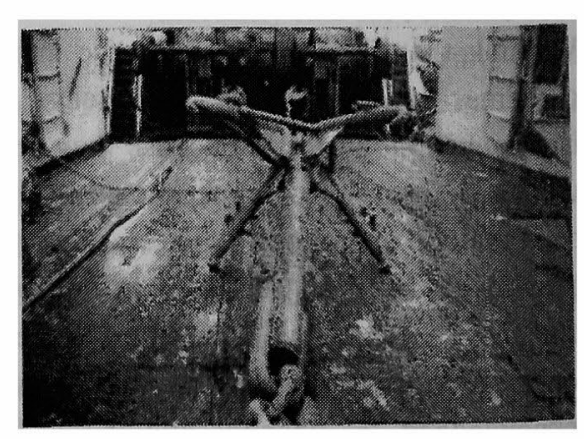

Fig. 1. Grapnel for retrieval of lost fishing gear. 

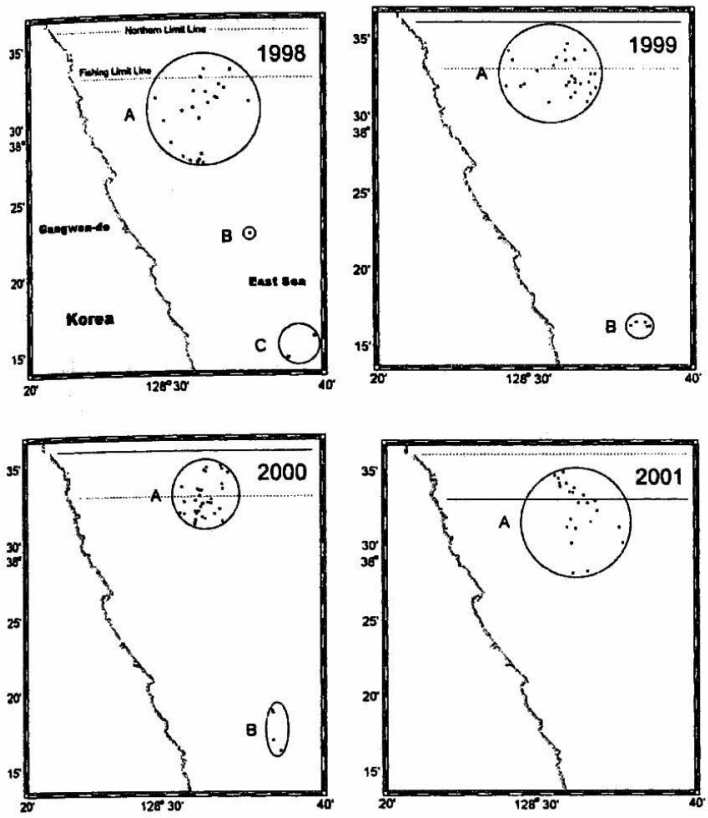

Fig. 2. Retrieved operation station.

Points indicate only the position where lost fishing gear was retrieved during the retrieval operation. A, B, C: trisect operation latitude and called by A, B, C.

August 1999 (26 days); from July to August 2000 (21days); and from May to July 2001 (38 days). The retrieval operation was conducted at the walleye pollack fishing ground on the east coast of Gosunggun, Gwangwon-do, around the Northern limit line (Fig. 2). We operated at the probable location for lost gillnet in cooperation with fishermen. Retrieval operation area was between Lat. $38^{\circ}-14^{\prime} \mathrm{N}$ and $38^{\circ}-$ $35^{\prime} \mathrm{N}$, and Long. $128^{\circ}-28^{\prime} \mathrm{E}$ and $128^{\circ}-40^{\prime} \mathrm{E}$. The retrieval area trisects Lat. $38^{\circ} 14^{\prime} \sim 35 \mathrm{~N}$ and shall be called A, B, C. The retrieved stations of lost fishing gear are shown in Fig. 2.

The retrieval operation for lost fishing gear by the trawler was conducted through the following procedure: 1) Move to a location where lots of lost fishing gear is likely to be scattered around, and shoot grapnel as the ship proceeds on with slow speed ahead. 2) Tow grapnel at a speed of 2 to 4 knots until it hooks up to lost fishing gear. 3) Once we think we hooked up lost fishing gear, judging from the vessel speed and change in the tension of the warp, stop the vessel and slowly haul it up to stern deck using only the power of the trawl winch. In a day, we repeated this process as above. 4) The retrieved lost fishing gear will be unloaded at the port and processed for separate collection (Fig. 3).

We measured the weight of the collected fishing gear using crane scales (Hookace- $\beta$, Bongshin) right after they were unloaded from the ship at the port. Accessories like sinkers, floats for fixing fishing gear and traps were measured by electronic scales (AD-05,
Cas). The working position was obtained by GPS (STR-1300, SGP-2500LA, Samyoung), and the depth by a fish-finder. The towed distance was obtained by the electronic chart (Navi-Sailor 2400 ECDIS, Transas). Data on the amount of walleye pollack catch is available from the department of marine $\&$ fishery in Gosung-gun.

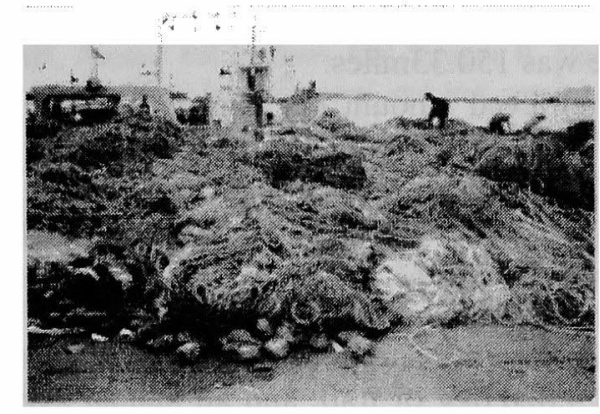

Fig.3. Retrieved lost gillnets.

\section{RESULTS}

The retrieved fishing gear consists of walleye pollack bottom gill nets and crab, shrimp traps. The retrieval operation for discarded fishing gear was conducted a total of 63 times in 24 days in 1998: 59 times in 21 days in area $\mathrm{A}$, once in 1 day in area $\mathrm{B}$, and 3 times in 2 days in area C. A total of 62 times in 26 days in 1999: 54 times in 23 days in area A, and 8 times in 3 days in area C. A total of 62 times in 21 days in 2000: 55 times in 19 days in area A, and 7 times in 2 days in area C. A total of 112 times in 38 days in 2001 in area A.

In 1998, retrieved lost fishing gear were 23 times out of 59 attempts of casting and hauling up anchor in area A. 626 tons of bottom gill net and $619.7 \mathrm{~kg}$ of trap were retrieved, and the towed distance was 59.03 miles. In B area, $479.6 \mathrm{~kg}$ of trap were retrieved in one attempt of shooting and hauling up grapnel, and the towed distance was 1.11 miles. In area $\mathrm{C}, 83$ tons of bottom gill net and $58.4 \mathrm{~kg}$ of trap were retrieved in two attempts of shooting and hauling up grapnel, and the towed distance was 4.03 miles.

In 1999, retrieved lost fishing gear were 28 times out of 54 attempts of shooting and hauling up grapnel in area A. 450 tons of bottom gill net and $2,846.9 \mathrm{~kg}$ of trap were retrieved, and the towed distance was 56.78 miles. In area $\mathrm{C}$, retrieved lost fishing gear was 5 times out of 8 attempts of shooting and hauling up grapnel. Eleven tons of bottom gill net was retrieved, and the towed distance was 9.35 miles.

In 2000 , retrieved lost fishing gear were 32 times out of 55 attempts of shooting and hauling up grapnel in area A. 517 tons of bottom gill net and $274.8 \mathrm{~kg}$ of 
trap were retrieved, and the towed distance was 78.45 miles. In area $C$, retrieved lost fishing gear was 4 times out of 7 attempts of shooting and hauling up grapnel. 32 tons of bottom gill net and $38.6 \mathrm{~kg}$ of trap were retrieved, and the towed distance was 5.31 mile.

In 2001, retrieved lost fishing gear was 23 times out of 112 attempts of shooting and hauling up grapnel in A area. 654 tons of bottom gill net and $502.6 \mathrm{~kg}$ of trap were retrieved, and the towed distance was 150.33 miles.

The retrieved amount per haul was 11.27 tons in $1998,7.48$ tons in $1999,8.85$ tons in 2000 , and 5.84 tons in 2001. The total towed distance was 64.14 mile in $1998,66.13$ mile in $1999,83.76$ miles in 2000 , and 150.33 mile in 2001 .

In all, during the 4 years of operation from 1998 to 2001 , we retrieved a total of 2,373 tons of bottom gill net and $4,820.6 \mathrm{~kg}$ of trap, and an annual average of 593.25 tons of bottom gill net were retrieved. Bottom gill nets accounted for the biggest portion of retrieved fishing gear.

Table 1 show the retrieved amount of gill net, only when lost fishing gear was retrieved during the retrieval operation. The retrieved rate of lost gillnet was $39.7 \%$ in 1998 , as lost fishing gear were retrieved 25 times out of 63 attempts of shooting and hauling up grapnel, $53.2 \%$ in $1999,58.1 \%$ in 2000 and $20.5 \%$ in 2001 . Retrieved lost gill net was 709 tons in 1998, 461 tons in 1999, 549 tons in 2000 and

Table 1. The retrieved amount of gill net

\begin{tabular}{cccccc}
\hline \hline Year & $\begin{array}{c}\text { Retrieved } \\
\text { haul } \\
\text { number of } \\
\text { times }\end{array}$ & $\begin{array}{c}\text { Gill net } \\
(t)\end{array}$ & $\begin{array}{c}\text { Towed } \\
\text { distance } \\
(\text { mile })\end{array}$ & $\begin{array}{c}\text { Amount } \\
\text { per dist. } \\
(t / m i l e)\end{array}$ & $\begin{array}{c}\text { Retrieved } \\
\text { depth } \\
(\mathrm{m})\end{array}$ \\
\hline 1998 & $25(63)^{* 1}$ & 709 & 31.18 & 22.74 & $75 \sim 860$ \\
1999 & $33(62)$ & 461 & 36.67 & 12.57 & $50 \sim 700$ \\
2000 & $36(62)$ & 549 & 44.09 & 12.45 & $294 \sim 995$ \\
2001 & $23(112)$ & 654 & 36.67 & 17.98 & $156 \sim 1000$ \\
\hline
\end{tabular}

*1: Total haul number of times

654 tons in 2001 . The retrieved amount of bottom gill net per towed mile was 22.74 tons in $1998,12.57$ tons in $1999,12.45$ tons in 2000 and 17.98 tons in 2001. The depth displayed the shallowest point and the deepest point during operation: 75 860 meters in $1998,50 \sim 700$ meters in 1999, 294-995 meters in 2000 , and $156-1,000$ meters in 2001, which shows that the operation was done mostly in deep sea. Minimum depth in 1998 and 1999 was low due to movement in shallow places because we cannot take huge lost gillnet aboard immediately in deep places.

Fig. 4 shows changes in total amount of retrieved lost fishing gear each year, the retrieved amount per total towed distance and the amount of walleye pollack catch. The weight of retrieved discarded fishing gear was 710.1 tons in $1998,463.8$ tons in $1999,549.3$ tons in 2000, and 654.5 tons in 2001 . The retrieved amount per total towed distance was the largest in 1998, with 11.07 tons, and then gradually decreased to 7.01 tons in $1999,5.65$ tons in 2000 , and 4.35 tons in 2001. Meanwhile, the amount of walleye pollack catch reduced each year, which indicates that it has no direct correlation with the retrieved amount of discarded fishing gear: $2,817.4$ tons in 1998, 1,146.6 tons in 1999, and 931.7 tons in 2000.

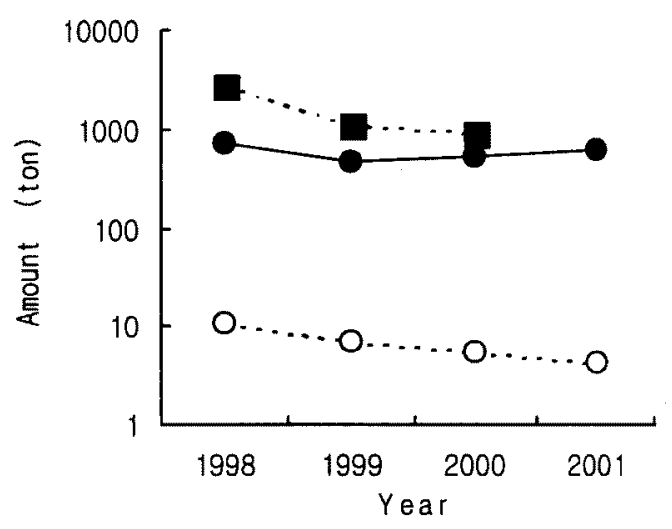

Fig. 4. Changes in total amount of retrieved fishing gear $(\bigcirc)$, catch of walleye pollack $(\square)$ and retrieved amount per towed mile $(O)$.

\section{DISCUSSION}

Worldwide estimates of losses and discards of commercial fishing gear range from 1,350 tons to 135,000 tons each year. ${ }^{6)}$ Merrell $^{7)}$ estimated that 1,635 tons of fishing gear was being lost annually in just the waters off Alaska. Kanehiro et al ${ }^{8)}$ collected from the trawl net $121.4 \mathrm{~kg}$ of marine litter on the seabed of Tokyo bay during the 1989 to 1993 period. Considering the fact that we were not able to retrieve all the lost fishing gear at the walleye pollack fishing ground on the east coast of Korea, it is likely that the total amount of lost fishing gear is far greater than the annual average of 593.25 tons of fishing gear which we retrieved in our research. It is said that huge amount of fishing gear is lost because too many fishing gear are being placed within such a limited fishing ground near the border between South Korea and North Korea so that they get entangled with each other, and because seabed topography is so winding northwards that bottom gill nets are pushed across the fishing limit line or are fouled by the impact of tide, 
storm and surge.

We can say that the fishing ground is getting cleaned gradually since the retrieved amount per towed mile is declining every year (Fig. 4). However, the amount of walleye pollack catch tends to decline each year despite our efforts to retrieve lost fishing gear, which seems to have a bigger effect in result of the reduction of walleye pollack resources and decrease in migration amount from the North Korea due to the rise in water temperature caused by global warming. But, environment broken once needs fairly great deal of time to get back.

The weight of one net of a retrieved bottom gill net under wet conditions is estimated to be $47.3 \mathrm{~kg}$, and 2,373 tons of retrieved bottom gill net is equivalent to about 50,169 nets, or about $2,508 \mathrm{~km}$, which is estimated to be worth about $\$ 3,030,207.6$, but the new bottom gill net costs $\$ 60.4$ per net. This figure implies that lost or discarded fishing gear not only destroys fishing ground but also brings huge economic losses.

We should find ways, like naming fishing gear, reducing fishing boats, enhancing the acoustic detect ability of fishing gear, ${ }^{9)}$ and developing degradable fishing gear ${ }^{10)}$ to reduce marine pollution by fishery.

\section{ACKNOWLEDGMENTS}

I would like to express my appreciation to the officials of the Department of Marine \& Fishery, Gosung-gun, Gwangwon-do, the Gosung-gun Fisheries Cooperatives, and crew of the Himangbobg and the Cheonkyung for their support.

\section{REFERENCES}

1. Arimoto T. Technical approach on fishing impact. Round table meeting for fishing technology 2001; 44: 1-10(in Japanese).

2. Carr HA, Blott A. A study of ghost gillnets in the inshore waters of southern New England. Proceeding of the

Fisheries Conservation Engineering Workshop. 1991; 2-5.

3. Laist DW. Marine debris entanglement and ghost fishing. Proceedings of the Solving Bycatch Workshop, 25-27,1995, Seattle, Wasthinton. 1996; 33-40.

4. Carr AH, Amaral EH Hulbert AW, Cooper R. Underwater survey of simulated lost demersal and lost commercial gill nets off New England. Proceeding of the Workshop on the Fateand Impact of Marine Debris, 1985; 27-29.

5. Matsuoka T, Osako T, Miyagi M. Underwater observation and assessment on ghost fishing by lost fish-traps. Proceedings of the Fourth Asian Fisheries Forum. 1997; 179-183.

6. Pruter A T. Sources, Quantities and Distribution of Persistent Plastics in the Marine Environment. Mar. Pollut. Bull. 1987; 18: 305-310.

7. Merrell TR. Jr. Accumulation of plastic litter on beaches of Amchitka Island, Alaska. Mar. envir. Res. 1980; 3: 171-184.

8. Kanehiro HT, Tokai T, Matuda K. Marine litter composition and distribution on the seabed of Tokyo bay. Fisheries Eng. 1995; 31: 195-199.

9. Goodon AD, Klinowska M, Bloom PRS. Enhancing the acoustic detectability of gillnets. Rep. Int. Whal. Commn. 1994; 585-595.

10. Andrady AL, Pegram JE, Song Y. Studies on enhanced degradable plastics. 2. Weathering of enhanced photodegradable polyethylene under marine and freshwater floating exposure. J. Environ. Polymer Degrad. 1993; 1: 117-126. 